Professora Assistente do Depto de Psicologia da UFPE. Mestre en Psicologia Social e do

A necessidade de estudar mais profundamente a relaçấo do trabatho com os processos psíquicos tem sua origem no começo do século XX, com ampla aplicaça dos princípios tayloristas criados com o objetivo de racionalizar o trabalho.

Com o desenvolvimento industrial e a acentuaçào da divisào entre concepcia e execuça do trabalho. a aplicaçào direta destes princípios trouxe graves prejuizos à saúde fisica e mental dos trabalhadores, em consequencia de prolongadas jornadas de trabalho, ritmo acelerado da produçaro, fadiga fisica, e sobretudo, atutomaçâo, nào participação no processo produtivo e parcelamento das tarefas.

Fstudos desenvolviclos na Francal por Dejours (1987) criticam o modelo taylorista e demonstran que é a organizaca do trabalho a responsivel pelas consequências penosias ou favoríveis para of funcisnamento psiquices do trabalhador.

Oatutor afirma que podem ocorrer vivencias de prazer $\mathrm{e} / \mathrm{ou}$ de sofrimento no trabalho, expressas por mejo de sintomas especificos relacionatas as contextosócio-profissional e a propria estrututa de personalidade

"A organização do trabalho exerce sobre o homem uma ação específica, cujo impacto é o aparelho psiquico. Em certas condiçòes emerge um sofrimento que pode ser atribuído ao choque entre uma história individual, portadora de projetos, de esperanças e de desejos e uma organização do trabalho que os ignora." Dejoms ( 1087 )

Wisner (1994) compartilha essats idéias, consiclerando que a dimensào psiquica do traballho definida em termoss de níveis de conflitos no interior da representação consciènte ou inconsciente das relaçóes entre pessoa e a organizaçào do traba-

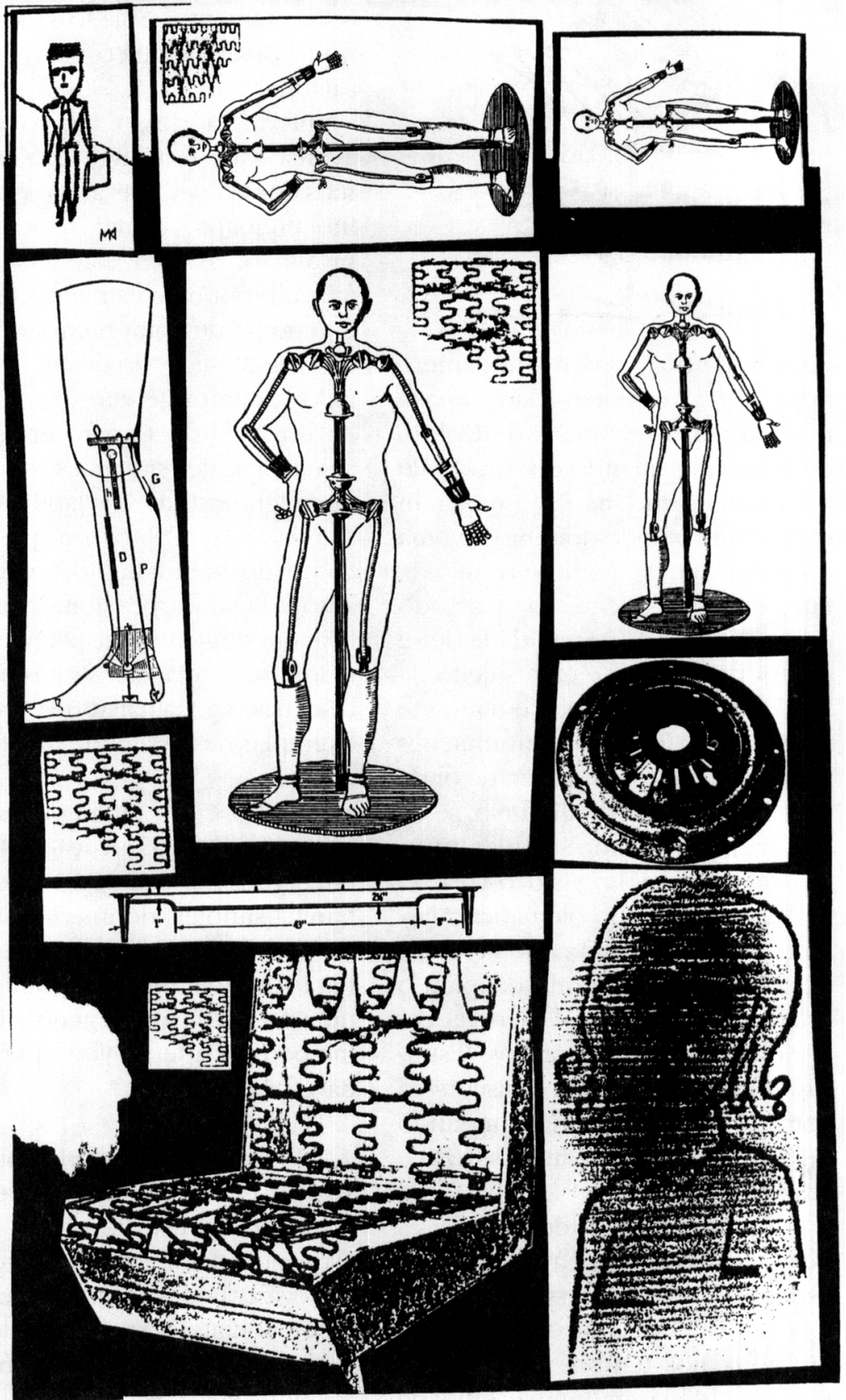

\section{Aspectos Psicodinâmicosda} Relação Homem-Trabalho: as contribuiçóes de C. Dejours 
lho, interferem na percepçào positiva ou negativa do trabalhador acercá do seu trabalho.

Os indivíduos reagem de forma diferente as dificuldades das situaçoes de trathatho e chegam a este trabalho com a sua história de vida pessoal. Os problemas, neste contexto. nascen de relaçoes conflituosas. De un lado, encontral-se a pessoa e sua necessidade de prazer; $\mathrm{e}^{2}$ cho outro, a organizaça, que tende â instituição de um autonatismo e à adaptação do trabalhador a um cleterminado modelo.

A sistematizaça dos concestos acima apresentados tên origem na psicopatologia, especificamente na Psicanálise, tendo sido discutidos por Freud nos seus estudos de 1930 no texto "Mal estar da civilizaçào", o que de certa forma dá consistênciá à proposta da disciplina, denominada pelo próprio Dejours desde 1990 de psicodinâmica do trabalho.

Para Freud, a atividade do homem caminha em duas direçoes: busca de ausência de sofrimento e desprazer, e de experiência intensa de prazer.

O prazer está relacionado à sátisfaçào de necessidades representadas em alto grau pelo sujeito, tornando-se desta forma, utma manifestação episódica, tendo em vista as contrariedades impostas pela civilização. A esse conceito, acrescenta-se a afirmação de Dejours in Betjol (1994), de que o prazer do trabalhador resulta da descarga de energia psíquica que a tarefa autoriza.

Por outro lado o sofrimento é caracterizado por sensaçôes desagradáveis provenientes da nào satisfaçào de necessidades. Estas são de origem inconsciente e estão relacionadas aos desejos mais profundos dos sujeitos, revelados muitas vezes ao consciente em forma de projetos e expectativas de vida.

Freud nos seus escritos de 30 , considera que o sofrimento ameaça o suịeito em três direções: a do próprio corpo, do mundo externo e dos relacionamentos com os outros homens.

Assim sendo, o sofrimento não é originado na realidade exterior, mas sim, nas relaçòes que o sujeito esta- belece com esta realidade. É a solicitaçào pulsional do meio externo que conduz a uma representação penosá.

O trabalho, como parte do mundo externo ao sujeito e do seu próprio corpo e relaços socjais, representa uma fonte de prazer ou de sofrimento, descle que as condicoes externas oferecidas atendam ou nào à satisfição dos descjos inconscientes.

A atividade profissional constitui fonte de satisfação, se for livremente escolhida, isto é, por meio de sublimação, tornar possivel o uso de inclinaçôes existentes, de impulsos instintivos (pulsionais) persistentes ou constitucionalmente reformados. No entanto, como caminho para a felicidade, o trabalho não é altamente prezado pelos homens. Não se esforçam em relação a ele como o fazem em relação a outras possibilidades de satisfação. A grande maioria das pessoas só trabalha sob pressão da necessidade, e esta aversão humana ao trabalho suscita problemas sociais extremamente dificeis. (Freud, 1974).

Desta forma consideramos que a busca do prazer no trabalho e a fuga do desprazer constituem um desejo permanente para o trabalhador em face das exigências contidas no processo, nas relaçòes e na organizaçào do trabalho. Este, muitas vezes, só oferece condiçōes contrárias a este propósito, gerando desprazer, expressso numa vivência de sofrimento, com sintomas especificos, transformando o trabalho em necessidade de sobrevivência, no lugar de fonte sublimatória de prazer.

Neste sentido, Guareschi \& Grisci (1993) afirma ser o sofrimento psíquico diferente do físico. O físico é visível, o psíquico é invisivel, sendo em grande parte vivenciado de forma particular por cada sujeito, ou seja, quando as condiçôes externas salientam esta cadeia, haverá um reencontro das relações parentais infantis com a realiclade atual.

Para Dejours (1990), a qualidade do sofrimento está relacionada à cadleia biográfica e à histótia de vida do sujeito, ou seja, quando as condiçoes externas salientam esta cadeia, haverá um reencontro das relaçoes parentais infantis com a redliclade atual.

Desde os anos 70, a disciplina psicopatologia do traballo vem estudando a interface homem e organizaçào do trabalho. De um lado, a organizaçăo do trabalho, caracteriZiacla pelá rigideze por se constituir un sistema de imposiçoes e restricòses essencialmente técnicals e imoveis como jroposto no tayk)rismofordismo. De outro lado, of funcionamento psiquico, caracterizado pela liberdade de imaginaçào e expressào dos desejos inconscientes do trabathador.

Numa segunda etapa, nos anos 90, já denominada, psicodinâmica do trabalho, a organizaçào do trabalho é caracterizada pela mobilidade e mutabilidade, e o funcionamento psíquico, pelos mecanismos de mobilizaçào subjetiva, tendo o trabalhador um papel ativo diante das imposiçôes e a possibilidade de transformar concretamente as situações de trabatho, para que estas possam trazer benefícios para a saúde mental.

Dejours in Betiol (1994) afirma que as condições de trabalho prejudicam a saúde do corpo do trabaIhador, enquanto a organizaçào do trabalho atua no nivel do funcionamento psíquico. A divisào de tarefas e o modo operatório evocam o sentido e $o$ interesse de trabalho para o sujeito, e a divisão de homens mobiliza os investimentos afetivos, a solidariedade e a confiança.

Dejours (1987) conceitua organizaçào do trabalho como a diviš̃o do trabalho, o conteúdo da tarefa (à medida que ele dela deriva), o sistema hierárquico, as modalidades de comando, as relaçòes de poder, as questões de responsabilidade.

Os aspectos relativos à divisào $\mathrm{e}$ conteúdo das tarefas, sistema hierárquico e relaçòes sócio-protissionais săo estabelecidos a partir de 
padrões específicos do sistema de produçào que, por sua vez, determina a estrutura organizacional na qual o trabalho é desenvolvido.

Desta forma, cada categoria profissional está submetida a um modelo específico de organização do trabalho, o qual pode conter elementos homogêneos ou contraditórios, facilitadores ou não da saúde mental do trabalhador. Esta definição depende dos interesses econômicos, ideológicos e políticos daqueles que dominam o processo produtivo.

Aprofundando seus estudos, Dejours e Abdoucheli (1990) passam a considerar que a organização do trabalho resulta das relações intersubjetivas e sociais dos trabalhadores com as organizaçōes. Dinamicamente sào estabelecidos compromissos entre os homens para definir regras defensivas e regras de ofício, e entre níveis hierárquicos para negociar essas regras, e obter novos compromissos renegociáveis posteriormente, caracterizando-se pela sua evoluçào em função dos homens, do coletivo, da história local e do rempo.

Neste sentido, Abrahào (1986), ainda, demonstra que a organização do trabalho pode ser distinta para várias empresas com os mesmos processos técnicos, para empresas diferentes, e até variar de um local para outro dentro da mesma empresa.

Considerando esta afirmativa, a organizaçào do trabalho contém além deste aspecto da variabilidade, o caráter processual e dinâmico, que pressupõe uma relação intersubjetiva e social, à medida que a sua definiçào técnica é sempre insuficiente com relação à realidade produtiva, por esta exigir sempre reajustes e reinterpretaçòes por parte dos sujeitos.

Desta forma, o trabalho nào é lugar só do sofrimento ou só do prazer, mas é proveniente da dinâmica interna das situaçôes e da organização do trabalho, ou seja, é produto desta dinâmica, das relaçôes subjetivas, condutas e açōes dos trabalhadores, permiticlas pela organização do trabalho.
Assim sendo, podemos considerar que tanto o modelo de organizaçào do trabalho prescrito pela organização, como as relações subjetivas dos trabalhadores com o trabalho têm papel fundamental na determinação de vivências de prazer, com consequências para a produtividade.

Por estas razôts, o estudo deste tema pode trazer algumas contribuições para a empresa, como o questionamento do modelo prescrito e sua influência na produçào, demonstrando que a gestão coletiva da organização do trabalho permite a transformação do sofrimento ou o prazer e possibilita o engajamento do trabalhador na atividade sem maiores prejuizos à sua saúde mental.

Nesta perspectiva, a psicodinâmica identifica que o trabalho humano năo ocupa um lugar marginal dentro da construção da identidade do sujeito, e que deve ser dada ênfase ao estudo da sublimação, ao invés de processos patológicos, porque a energia sublimada é essencial para a construção e a manutençào da economia psicossomática de cada um.

Em termos ideológicos, a sublimação no trabalho pode suscitar questionamentos a respeito do seu papel no processo de alienaçào. Por isso vale destacar que a sublimação não significa necessariamente resistência às mudanças, bem como pressupòe criatividade e participação do trabalhador, nảo constituindo um processo passivo e conformado diante das imposições das situações de trabalho, mas sim, um resultado de uma negociação bem sucedida entre desejos inconscientes do sujeito e a realidade.

Desta forma, segundo a psicodinâmica do trabalho, a relação homem-trabalho deve ser estudada do ponto de vista do normal e não apenas do patológico. Dejours \& Abdoucheli (1990) consideram a possibilidade do trabalhador, por não suportar o sofrimento, de transformá-lo em criatividade, e, consequentemente, em prazer, ao invés de utilizar como único recurso as estratégias defensivas.

A transformação deste sofrimento, originado na rigidez da organizaçào do trabalho, em criatividade depende de dois elementos: a ressonância simbólica e o espaço público de discussão coletiva.

A ressonância simbólica ocorre quando há uma compatibilização entre as representaçôes simbólicas do sujeito, seus investimentos pulsionais e a realidade de trabalho:

"A ressonância simbólica articula o teatro privado da história singular do sujeito ao teatro atual e público do trabalho, abrindo assim uma problemática socialmente referenciada da sublimação e do prazer no trabalho".

Para ocorrer esse processo, é necessário que a tarefa tenha um sentido para o sujeito, com base na sua história de vida. Assim sendo, Rodrigues (1992) compartilha a idéia de Dejours, que considera as dificuldades vivenciadas nas relações infantis com os pais como impeditivas para o sujeito vivenciar o processo de ressonância simbólica.

Neste sentido, o trabalho pode

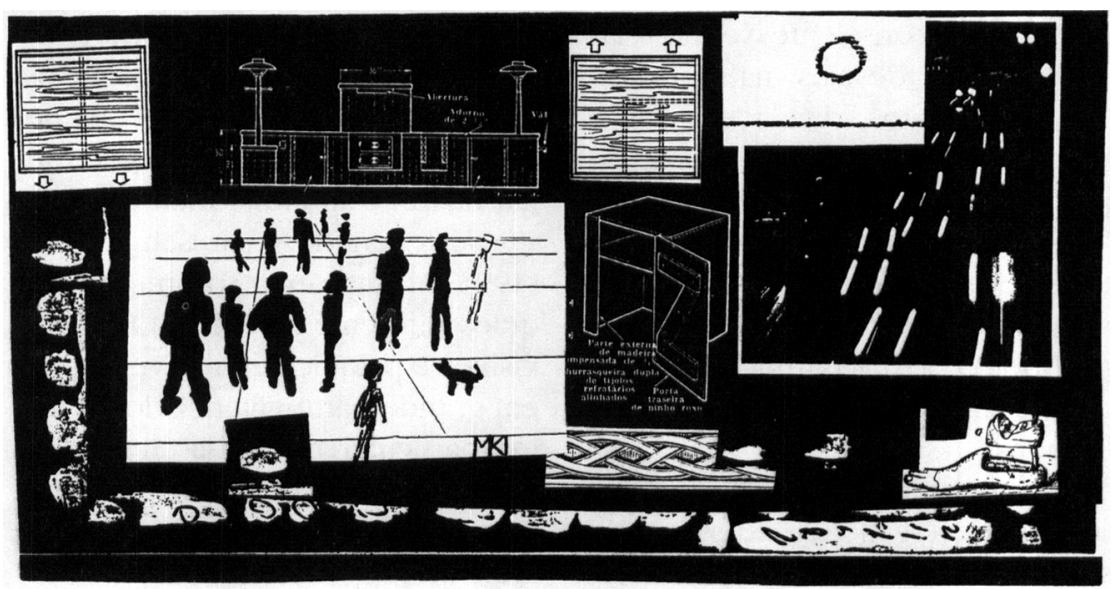




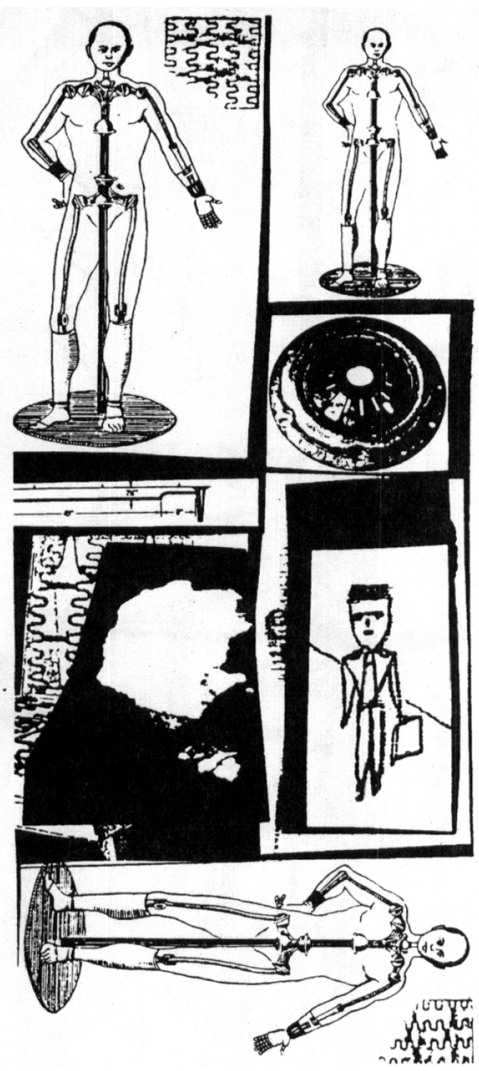

ser considerado como o lugar de satisfação sublimatória, quando o trabalhador transfere sua energia pulsional, que inicialmente é dirigida para as figuras parentais com objetivo de satisfaçâo imediata, para as reałçòes sociais com satisfaçào mais altruísta.

A ressonância simbólica é a reconciliação entre o inconsciente $e$ os objetivos da produção. Na maioria das vezes, os preceitos rígidos e o controle organizacional não permitem ou limitam o espaço para ressonância simbólica, đevido às exigências de responsabilidades, separação entre trabalho real e prescrito e entre concepçào e execução.

O espaço público é construído pelos próprios trabalhadores, constituindo o momento em que são partilhadas a cooperação, a confiança e regras comuns. Representa o espaço da fala, da expressão coletiva do sofrimento e da busca de mecanismos de transformação da situação vigente.

O sofrimento criativo não é sinônimo de prazer. Este pressupõe um investimento sublimatório, no qual o prazer sexual infantil será substituído pelo prazer no trabalho. Neste sentido, o trabalho tem que ser uma escolha para o sujeito e espaço da satisfação dos desejos inconscientes.

Nào obstante, o investimento sublimatório e a ressonância simbólica tem, muitas vezes, seu espaço delimitado pelas imposições da organização do trabalho, fazendo com que o trabalhador utilize outros recursos, como o uso da inteligência operária e o processo de reconbecimento simbolico para transformar o sofrimento em prazer.

A inteligência operária é conceituada por Dejours \& Abdoucheli (1990) como uma inteligência astuciosa, que tem raíz no corpo, nas percepções e na intuiçăo sensível do trabalhador, e, sobretudo, ela é uma inteligência em constante ruptura com as normas, regras, sendo fundamentalmente transgressiva.

Este tipo de inteligência é clenominado por Dejours (1995) como a intelligence de la pratique supondo que a atividade requer um ajustamento das relaçôes entre as prescriçôes das tarefas e obstáculos impostos pela organização do trabalho e a inteligência originada da experiência real do trabalhador e da sua concepçào sobre a atividade

Dejours (1992) amplia seus estudos e disto resultam alguns novos conceitos, que de certa forma representam a evolução e/ou sintese dos já desenvolvidos.

Assim sendo, ele cria o conceito de mobilizaçào subjetiva, processo que se caracteriza pelo uso da inteligência operária e pelo espaço público de discussòes sobre o trabatho. A utilização destes recursos pelos trabalhadores depende da dinâmica contribuiçào-retribuição simbólica, que pressupõe o reconhecimento da competência do trabalhador pelos pares e pela hierarquia.

O processo de mobilização subjetiva não é prescrito, sendo vivenciado de forma particular por cada trabalhador. Vale ressaltar que ele é fundamental no processo de gestão coletiva da organização do trabalho, à medida que evita o uso de estratégias defensivas ou de descompensaçâo psicopatológica.

Estes conceitos sistematizados permitem uma concepção de traba- lho vinculada aos processos sublimatórios e à transformaçào do sofrimento. Assim, considera três componentes irreclutiveis no trabalho: a atividade produtiva, a coordenação entre os agentes $e$ a mobilização subjetiva dos trabalhadores.

A atividade produtiva é resultado do uso da inteligência operária, que se manifesta no confronto entre o que é imposto pela organização do trabalho e as necessidades psíquicas do trabalhador. É uma espécie de resistência ao domínio dos conhecimentos e procedimentos padronizados e preconizados pela concepção e preparação do trabalho.

A coordenação das atividades singulares é implementada por meio da cooperação. Esta não é prescrita nem decretada; depencle da possibilidade de os agentes estabelecerem entre si relações intersubjetivas de confiança.

Os resultados das pesquisas sobre a análise da confiança entre pares mostram que ela não depende apenas dos requisitos afetivos e éticos, mas principalmente da visibilidade dos ajustamentos singulares utilizados frente às insuficiências e às contradiçòes da organização prescrita.

Esta visibilidade, por seu lado, é condicionada à qualidade do espaço da discussão sobre a organizaçao do trabalho, bem como da cooperaçào, que exige articulação, coordenação e evolução das regras de trabalho, com o objetivo de substituir ou complementar a organização de trabalho prescrita.

No processo de mobilização subjetiva, o trabalhador faz uso de sua personalidade e inteligência para se contrapor a uma racionalidade subjetiva específica gerada na situação de trabalho. Essa dinâmica se apóia no processo de contribuição-retribuição.

A contribuição é espontânea à organizaçâo do trabalho real e tem como retorno a retribuição simbólica, que se dá pelo reconhecimento, processo ao qual é atribuído a construção da identidade social e de realizaçào de si mesmo. Estes com- 
ponentes do trabalho demonstram que ele é resultado da interseção de três mundos: 0 objetivo, o social e $o$ subjetivo.

Desta forma, a organização do trabalho ê um compromisso resultante da negociação social simultânea entre os pares e os diferentes níveis hierárquicos.

Este modelo teórico da psicodinâmica é aplicado a qualquer situação de trabalho; entretanto, o estudo da normalidade não elimina os efeitos psicopatológicos que o trabalho pode exercer nos trabalhadores. Neste sentido, a normalidade não implica ausência de sofrimento, bem como o sofrimento não exclui o prazer.

$O$ sofrimento ou as defesas se instalam no momento em que os trabalhadores não têm a possibilidade de utilizar o processo de mobilização subjetiva, ou sentir prazer resultante do investimento sublimatório, seja por restriçōes de sua estrutura de personalidade, seja pelas imposiçôes do modelo de organização do trabalho.

As estratégias defensivas são definidas como um mecanismo pelo qual o trabalhador busca modificar, transformar e minimizar sua percepção da realidade que o faz sofrer. Este processo é estritamente mental, já que ele não modifica a realidade de pressão patogênica imposta pela organização do trabalho.

A diferença entre um mecanismo de defesa individual e coletivo reside no fato de que o primeiro permanece sem a presença física do objeto, porque ele está interiorizado, enquanto, que o segundo depende da presença de condiçôes externas e se sustenta no consenso de um grupo específico de trabalhadores.

As estratégias defensivas coletivas podem permitir ao sujeito uma estabilidade na luta contra o sofrimento, que, em outras situações, seria incapaz de garanti-la apenas com as suas defesas individuais.

Para o autor, a estratégia defensiva pode tornar-se um objetivo em si mesmo para enfrentar as pressôes psicológicas do trabalho, o que leva a um processo de alienaçâo, e assim, bloquear qualquer tentativa de transformação da situação vigente.

Quando essas estratégias se estabilizam, surge o desencorajamento, a resignação diante de uma situação que não gera mais prazer, mas só sofrimento.

Dejours in Betiol (1994) obteve como resultado de uma de suas pesquisas a tese do individualismo, que é um processo pelo qual os trabalhadores interpretam os fatos atuais das situações de trabalho de forma singular, e sem considerar a história que os produziu. Eles atribuem uma naturalização da casualidade, porque seria insuportável o desmantelamento do esquema defensivo e a confrontação com as causas do seu sofrimento no trabaIho.

Considerando as formulaçōes teóricas da psicodinâmica, podemos concluir que o trabalho pode favorecer condições estabilizadoras que neutralizam o sofrimento, muitas vezes existencial, assumindo este papel quando as exigências pulsionais corespondem aos desejos inconscientes do sujeito, e tem lugar o processo de sublimaçào e/ ou o processo de mobilização subjetiva, que permite a transformação do sofrimento.

$O$ estudo dos aspectos psicodinâmiços da relação homemtrabalho não pode desprezar que as vivências de prazer-sofrimento decorrentes da organização do trabatho são dialéticas, e por isso não podem ser estudados separadamente. Não obstante, podemos identificar elementos específicos da organizaçào do trabalho que favorecem uma ou outra vivência, assim como a dinâmica delas clecorrente. Isto só é possivel por meio da fala dos trabalhadores, do discurso manifesto e latente, da analise da palavra, que se constitui mediadora entre representações psíquicas e a realidade.

Por essas razões, cabe aos pesquisadores buscarem empiricamente a dinâmica que envolve a relação homem-trabalho, especialmente a psicologia do trabalho que tem no comportamento humano dentro das organizações o seu principal objeto de estudo.

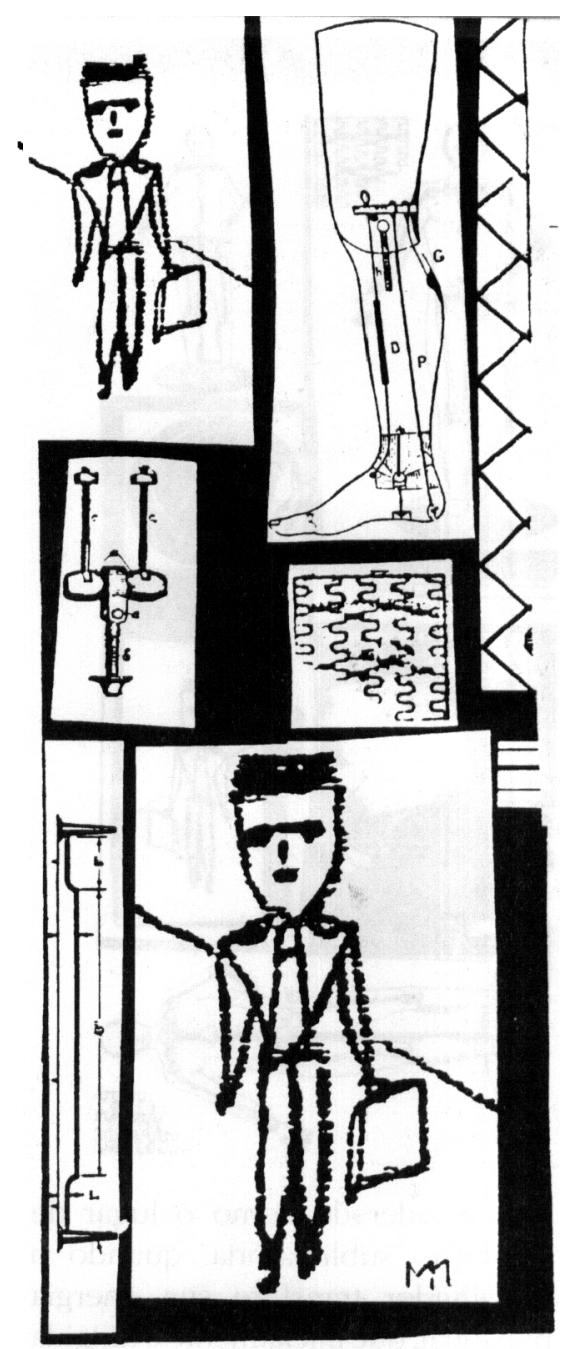

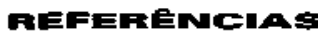
mUELUOCFAFICAE

ABRAHĀO. I. J. (1986). Organisation du Travail, Representation et Régulation du Sistem de Production. Etude Anthropotecnolagique de Deux Distilléries Situées Dans Deux Tissus Industriels Differents du Bresit. Tese de doutorado. Paris: CNAM.

DEJOURS, C. (1987) . A Loucura do Trabalho: Estudo de Psicopatotogia do Trabsho. Sāo Paulo: Cortez. \& Abdoucheli, E. 11990) . Itinéraire Theorique en Psychopathologie du Travail. Paris: Reve Prevenir, $20,4^{\circ}$ semestre. Dejours. C . (1992\}. Travall: Usure Mental (reedition). Paris.

11995). Le Facteur Humsin. Paris: Presses Universitaires de France.

BETIOL S. I. M. (1994). Psicodinamica do Trabalho - Contribusiches da Escola

Dejouriana a Análise da Relagao Prazer, Sofrimento e Trabalho. Sâo Paulo: Allas. Freud, S. (1974). Obras Completas. Rio de Janerro: Imago. XXi. PP.174

FREUD, S. \{1974\}. Obras Completes. Rio de Janeiro: Imago. XXI. PP. 174

GUARESCH, P.A. \& Grisci, I.L. .C. (1993). A Fala do Trabalhador. Petropolis: Vozes. RODRIGUES, A.M. (1992). Uma visâo do Sofrimento Humano nas Organizaçôes. In: Torres, S. L. O. LOrg.t. O individuo na

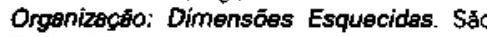
Paulo; Atles.

WISNER, A. (1994). A inteligencia no Trabalho. Săo Paulo. Fundacentro/Unesp. 